\title{
MECANISMOS DE RECLUTAMIENTO INDÍGENA EN LA MINERÍA DE PLATA. LÍPEZ (SUR DE LA ACTUAL BOLIVIA), SIGLO XVII*
}

\author{
INDIGENOUS RECRUITMENT MECHANISMS \\ FOR SILVER MINING. LIPEZ (SOUTH BOLIVIA) \\ 17TH CENTURY
}

\author{
Raquel Gil Montero \\ Consejo Nacional de Investigaciones Científicas y Técnicas, Argentina \\ <raquelgilmontero@conicet.gov.ar>
}

\begin{abstract}
Resumen. Este artículo analiza el mundo del trabajo de una mina de plata del siglo XVII ubicada al sur de la actual Bolivia, llamada San Antonio del Nuevo Mundo. A partir de este análisis se busca comprender cuáles fueron los mecanismos a través de los cuales se logró satisfacer la demanda de mano de obra que tenían los mineros y otros españoles de este asiento minero. Entre las dos formas extremas, el trabajo forzado y el libre, hemos encontrado que en San Antonio había una combinación de variados mecanismos de atracción y de coacción. Además hemos visto que la influencia del principal centro minero -Potosí- fue muy significativa en aspectos tales como la migración, la presencia de trabajadores especializados y la adquisición de conocimiento.
\end{abstract}

Palabras clave: minería de plata; siglo XVII; relaciones laborales.

Abstract. This article focuses on labour relations in a silver mine from the $17^{\text {th }}$ century, located in present-day Bolivia, called San Antonio del Nuevo Mundo. The purpose of this analysis is to understand which were the mechanisms used to fulfil the workers needs that miners and other Spaniards had. Between forced and free labour we found different combinations of coaction and attraction in San Antonio. The influence of the main miner center which was Potosi was also very important in our region regarding migration, presence of skilled workers and adquisition of knowledge.

Key words: silver mining; 17th century; labour relations.

Fecha de recepción: enero de 2013. Fecha de aceptación: mayo de 2013.

* El trabajo en bibliotecas y en archivos que sustenta el artículo fue realizado con una beca de la Fundación Humboldt-Thyssen, Alemania, y una de la Fundación John Simon Guggenheim. El trabajo de campo se realizó en el marco de un proyecto del Ministerio de Ciencia, Tecnología e Innovación Productiva/Ecos, Argentina y Francia. Agradezco a los evaluadores anónimos sus comentarios críticos.

Am. Lat. Hist. Econ., año 21, núm. 1, enero-abril, 2014, pp. 5-30 


\section{INTRODUCCIÓN}

comienzos de la década de 1640 se descubrieron en la actual pro-
vincia de Sur Lípez, Bolivia, unas importantes vetas de plata que
dieron lugar a un campamento que se llamó San Antonio del Nuevo Mundo. Estaba emplazado en un desierto de altura ubicado a más de 4500 metros sobre el nivel del mar, en una región donde la agricultura era prácticamente inexistente y la población escasa y dispersa, por lo que fue necesario llevar trabajadores desde los más diversos lugares del virreinato de Perú. ¿Qué mecanismos se pusieron en juego para poder satisfacer las necesidades de mano de obra de las minas e ingenios de San Antonio?

Los estudios sobre el mundo del trabajo en la minería de plata colonial de América Latina han dado cuenta de la existencia de diferentes modos de organizar la mano de obra, modos que variaban entre voluntarios y forzados, y que se habían dado en forma desigual a lo largo de la geografía, dependiendo -además- de los diferentes desarrollos regionales. ${ }^{1} \mathrm{El}$ trabajo forzado tuvo características muy diferentes en los principales centros mineros del continente ubicados en México y Perú: en el primero, el uso de este tipo de mano de obra fue limitado y se utilizó sobre todo en los primeros años de la actividad minera; en Perú, en cambio, fue muy importante sobre todo en Potosí y en Huancavelica, los dos asientos que se constituyeron en los pilares de la economía regional. En la mayoría de los centros mineros, no obstante, predominaba el trabajo voluntario. Esta fue una forma de trabajo que se incrementó rápidamente a partir del último cuarto del siglo XVI, en parte por la demanda creciente que hubo de especialistas que conocieran la técnica de la amalgama con mercurio (implementada en México en la década de 1550 y en Potosí en la de 1570), y en parte por la desaparición de la encomienda y la limitación geográfica que tuvo el trabajo forzado. ${ }^{2} \mathrm{El}$ hecho de que un trabajador fuera voluntario o que recibiera una paga, sin embargo, no significaba que existiera un mercado de trabajo como el moderno. Los dueños de minas o de ingenios de beneficiar mineral incorporaban trabajadores con métodos que alternaban mecanismos de atracción, con otros de reclutamiento más o menos forzado o de retención de la mano de obra. Las dos principales maneras de atraer población fueron la combinación de una oferta de mejores jornales (algo que se podía hacer en los asientos recién descubiertos y ricos) con el permiso que tenían los trabajadores de sacar mineral durante los fines de

${ }^{1}$ La bibliografía sobre minería colonial es muy abundante, sobre todo para el caso de México y de Potosí. En este trabajo hacemos referencia solamente a aquella que hemos utilizado expresamente en este artículo. Garner, "Long-term", 1988; Bakewell, "Mining", 1984; Brown, History, 2012, y Gavira, "Potosî", 2007.

${ }_{2}^{2}$ Bakewell, Miners, 1984. 
semana para su propio provecho. ${ }^{3}$ Una de las formas clásicas de retención de la mano de obra muy descrita para México fue el del endeudamiento, que parece haberse extendido menos en Perú. ${ }^{4}$ Los mecanismos compulsivos, por su parte, estaban vinculados principalmente a la condición de tributarios de los indígenas, que eran la mano de obra mayoritaria en esta minería. Este mecanismo varió desde formas directas (el servicio personal formó parte de las obligaciones incluidas en los tributos tempranos), a formas indirectas promovidas por la obligación de pagar en plata u oro. Esta última forma se vio favorecida por la tasación de los tributos en plata u oro, que se fue incrementando muy claramente a partir de la Tasa General del virrey Francisco de Toledo realizada en la década de 1570, y que forzó a los indígenas a "alquilarse" o a vender su producción para poder hacer frente a estas obligaciones fiscales. ${ }^{5}$

El caso más estudiado dentro de la minería de plata de Charcas ha sido Potosí con sus más de tres siglos de historia colonial, un asiento minero que lejos de ser un modelo es la excepción en los Andes. Sus minas proveyeron casi la totalidad de la plata del virreinato de Perú en el siglo XVI y más de 68\% en el XVII; gozó de un importante sistema de trabajo forzado casi desde sus comienzos (primero con las encomiendas, luego con la mita), y tuvo una productividad y duración que no se pueden comparar con ningún otro centro minero. ${ }^{6}$ San Antonio fue muy diferente a Potosí, pero sufrió claramente su influencia según pudimos apreciar en los resultados de nuestra investigación, por lo que su historiografía nos sugirió algunas de las líneas de estudio, tornándose una referencia ineludible en este artículo.

Las preguntas generales que guiaron nuestro análisis fueron tres: ¿quiénes eran y por qué habían ido a San Antonio en el siglo XVII estos migrantes indígenas (decisión individual en respuesta a las presiones coloniales, forzados por diferentes autoridades o como parte de sus estrategias colectivas)?; ¿ cuáles fueron los mecanismos que se utilizaron en el reclutamiento de la mano de obra minera y cuál fue su vínculo con la tributación? y ¿qué importancia tuvo para San Antonio la villa imperial de Potosí, que fue la principal escuela minera empírica de la región y el destino de la mayoría de los migrantes indígenas?7 San Antonio, finalmente, nos permite

${ }^{3}$ Zulawski, "Wages", 1987, y Gavira, "Reclutamiento", 2000.

${ }^{4}$ Bakewell, Minería, 1976.

${ }^{5}$ Assadourian, "Despoblación", 1989. Cabe recordar que se pagó significativamente menos en concepto de tributo en México que en Perú, aspecto que puede ser parte de la explicación de la participación de esta obligación en el trabajo compulsivo. 1973.

${ }^{6}$ Tandeter, "Ciclos", 2000; Bakewell, Miners, 1984; Cole, Potosi, 1985, y Barnadas, Charcas,

${ }^{7}$ Las preguntas están presentes, entre otros, en los trabajos de Assadourian, "Organización”, 1983; Saignes, "Ayllus", 1987, y Gavira, "Reclutamiento", 2000. 
mostrar algunas de las innumerables tonalidades de grises que hubo en las formas concretas de reclutamiento incluidas en un continuum que va desde el trabajo forzado al voluntario, así como la complejidad de análisis que presentan las fuentes.

\section{EL SIGLO XVII EN LOS ANDES}

El periodo en el que se inscribe la historia de San Antonio estuvo fuertemente afectado por las migraciones masivas que se originaron en las reformas de comienzos de la década de 1570 realizadas por el virrey Francisco de Toledo, en particular la Reducción General y la organización de la mita potosina. ${ }^{8}$ La reducción implicaba que la población indígena dejara de vivir dispersa por el área rural y se concentrara en pueblos creados a semejanza de los españoles, tanto en la distribución de calles, viviendas y espacios públicos, como en la concepción de orden social y del gobierno. Un porcentaje de los hombres de estas reducciones debía cumplir con una obligación rotativa y por turnos llamada mita. ${ }^{9}$ Aunque hubo diferentes mitas en el virreinato de Perú, la más importante para nuestras preguntas es la potosina, que implicó que tributarios de 16 provincias acudieran a dicha villa a servir en las minas y en los ingenios de moler metal. Aunque debían ir en forma obligada a Potosí, recibían una paga que estaba muy por debajo de la de los trabajadores voluntarios. Además debían realizar las peores tareas: en su gran mayoría los mitayos eran apiris (quienes sacaban el mineral de las minas en unas bolsas de cuero cargadas a sus espaldas), o incorporaban el mineral ya seleccionado a los mazos de moler en los ingenios.

Casi un siglo después de las reformas toledanas el virrey duque de La Palata realizó otra visita general (1683) que permite observar la magnitud de los cambios operados en los Andes a lo largo de ese periodo. Todavía en ese momento seguían siendo visibles las consecuencias demográficas de la conquista -combinadas con las secuelas de las reformas toledanas- que se pueden sintetizar en una enorme migración forzada, importantes transformaciones ocurridas en las categorías tributarias y las huidas de quienes no podían o no querían cumplir con las obligaciones fiscales. En Charcas, menos de la mitad de la población indígena (44\%) fue empadronada por los funcionarios del duque de La Palata como originarios de las comunidades donde estaban residiendo, y el resto lo fue mayoritariamente como forastero o yanacona. ${ }^{10}$ Para los fines de esta síntesis, lo que nos interesa des-

\footnotetext{
${ }^{8}$ Rowe, "Incas", 1957, y Mumford, Vertical, 2012.

${ }^{9}$ Cole, Potosi, 1985; Bakewell, Miners, 1984, y Tandeter, Coacción, 1992.

${ }^{10}$ Sánchez, Indios, 1978.
} 
tacar es que en el siglo XVII ambas categorías implicaban que la mayoría de quienes se habían empadronado o sus antepasados habían migrado.

Entre Toledo y La Palata la redistribución de la población tributaria no había sido homogénea: las provincias que habían sido asignadas para cumplir con la mita potosina fueron las que más población habían perdido (por muerte o migración), mientras que los valles orientales y las nuevas ciudades y asientos mineros habían atraído migrantes. El sur de Charcas, esto es el entorno de Potosí, comenzó a tener un mayor peso demográfico, en parte porque muchos de los que asistían a la mita con sus familias se quedaban en la cercanía. ${ }^{11}$ Aunque la población indígena había migrado en forma muy significativa desde tiempos prehispánicos, ${ }^{12}$ los movimientos de población del siglo XVII ocurridos en un contexto de debacle demográfica transformaron profundamente la geografía de los Andes. Estos movimientos tuvieron, además, un impacto significativo en el sistema de recolección de impuestos y en la organización de la mita, porque ambos estaban basados en la visita general realizada por el virrey Toledo. A lo largo del siglo XVII tanto el pago de los tributos como los contingentes de la mita disminuyeron fuertemente. Las autoridades coloniales eran conscientes de lo que ocurría, aunque con frecuencia se declararon impotentes para detener los flujos de población. ${ }^{13}$ Pero no todas eran quejas, hubo quienes se beneficiaron por estas migraciones y presionaron para que la situación no se modificara. Miles de españoles que habían sido excluidos de la mita fueron beneficiados por la llegada de trabajadores que huían de esta carga dirigiéndose a sus haciendas o a sus minas para conseguir la plata con la que podían pagar sus tributos o sus reemplazos en el trabajo forzado. La mayor preocupación de los funcionarios siguió centrada en la mita y en el reparto de la mano de obra minera, entre otras cosas porque esta actividad seguía siendo en aquel momento la principal fuente de ingreso de las Cajas Reales de Charcas. ${ }^{14}$

Aunque la mita era tan importante, durante el siglo XVII la mayoría de los trabajadores de Potosí eran indios alquilados a quienes se llamaba mingas, que cobraban en forma diferente según cual fuera la actividad que desarrollaban. Muchos mitayos preferían trabajar como mingas, tanto en Potosí como en otros asientos mineros, porque con lo que ganaban podían pagar su reemplazo en la mita. Justamente uno de los reclamos de los azogueros potosinos era que los nuevos asientos (como San Anto-

\footnotetext{
${ }^{11}$ Evans, "Migration", 1990, pp. 62 y ss.

${ }^{12}$ Murra, Formaciones, 1975; Buren, "Rethinking”, 1996, y Mumford, Vertical, 2012.

${ }^{13}$ Zagalsky, "Mita", 2012.

${ }^{14}$ Klein, Finanzas, 1994.
} 
nio) tenían mayores ventajas para los indígenas porque ofrecían mayor paga, lo que generaba ausencias generalizadas. ${ }^{15}$

\section{San Antonio del Nuevo Mundo}

Hacia la década de 1640 ya se habían descubierto algunos otros minerales de plata en la cercanía de la región donde se encontraron las vetas que dieron origen a San Antonio, pero ninguno tenía por entonces una población significativa. Los habitantes locales eran mayoritariamente pastores especializados de llamas que vivían dispersos en un enorme territorio donde la agricultura era (y es) prácticamente imposible (véase mapa 1). ${ }^{16} \mathrm{El}$ campamento inicial de San Antonio creció rápidamente hasta convertirse en la capital del corregimiento, lugar de residencia de las autoridades civiles y religiosas y de un abundante y variado conjunto de moradores. Aunque no tenemos datos completos, estimamos -a partir de diversas fuentes- que su población debió superar los 5000 habitantes. ${ }^{17}$ La ubicación de San Antonio y la distancia que había a los centros más cercanos de abastecimiento obligó a desarrollar una importante logística para proveerla de todo lo necesario, desde la alimentación, los insumos mineros y los elementos para la construcción (sobre todo madera y hierro). Y, por cierto, fue necesario abastecerla de la mano de obra que era muy escasa en la región.

El pico de producción de San Antonio debió ubicarse en torno a $1655{ }^{18}$ Hasta ese momento se habían extraído depósitos superficiales y muy ricos, fáciles de trabajar, que se fueron agotando. El trabajo, entonces, se tornó más difícil y costoso influyendo en los rendimientos que

\footnotetext{
${ }^{15}$ Esta competencia por la mano de obra ha sido analizada para el caso de Oruro en Escobari, "Extravagantes", 1997, y Gavira, "Potosî", 2007.

${ }^{16}$ La mayoría de la población de Lípez se concentraba al sur del salar de Uyuni, donde era posible la agricultura al secano de quinua. En la visita de 1602 la distribución de la población era la siguiente: $87 \%$ vivía al sur del salar (en el mapa 1: Quemes, Chuquilla, Colcha, Cheucha, Chuica), 9\% al norte del salar (Llica y Tagua) y 4\% en el sureste (San Antonio del Nuevo Mundo, Esmoruco y Santa Isabel). Padrón de Lípez de 1602, en Archivo General de la Nación (en adelante AGN), sala 13-18-6-5.

${ }^{17}$ Las estimaciones se basan en los restos arqueológicos de San Antonio, en los inventarios de ingenios y en los juicios que permiten estimar la cantidad de trabajadores que tenían, en los padrones de tributarios y cálculos de población realizados al inicio de la explotación y hacia el final de la misma.

${ }^{18}$ Bakewell, Plata, 1988. La producción exacta de este asiento minero no ha podido calcularse porque se registraba en las Cajas Reales en forma conjunta a la de toda la provincia de Potosí, excepto la del Cerro Rico. Nos hemos basado, entonces, en las estimaciones que realizó Peter Bakewell en la bibliografía citada.
} 


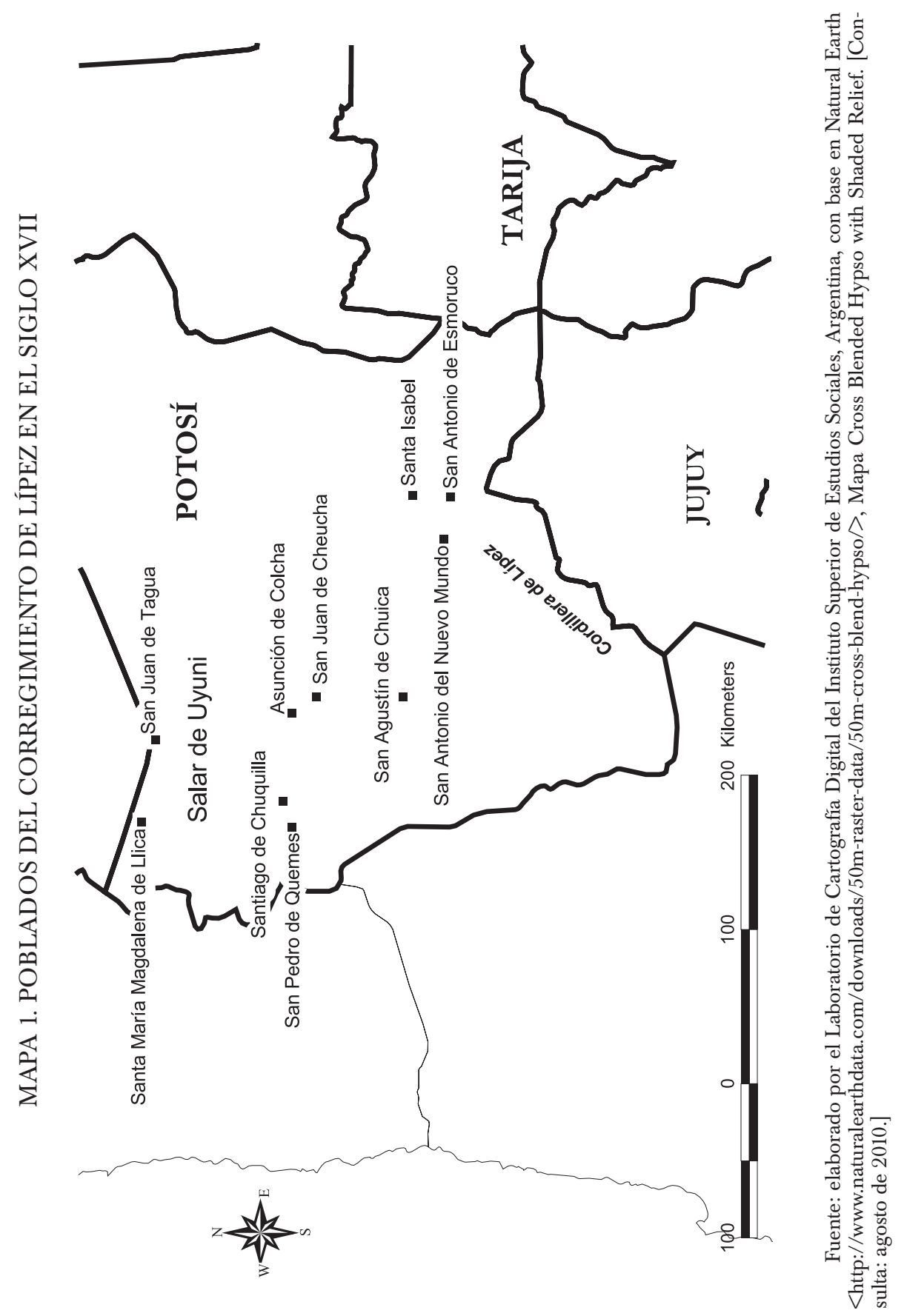


disminuyeron notablemente. En la década de 1660 San Antonio vivió una crisis relativa en la que algunos azogueros, mineros y trabajadores abandonaron el lugar. A comienzos de la década de 1670, un azoguero potosino llamado Antonio López de Quiroga decidió construir un socavón para desagotar al menos las vetas principales del asiento. El trabajo comenzó en diciembre de 1672 y terminó en enero de 1678, con jornadas completas (día y noche), parando únicamente los jueves y viernes santos. El impacto que tuvo este socavón se pudo observar en las Cajas de Potosí (donde San Antonio debía pagar los impuestos a la producción de plata): en 1678, cuando se habían desaguado las vetas, ingresó en las Cajas en concepto de quinto real una cantidad de plata seis veces mayor que la del año anterior, cantidad que fue creciendo sin interrupción hasta 1683. A inicios de la década de 1680, aunque la producción seguía siendo buena, las tareas se habían hecho más complejas y el trabajo más caro, ya que en muchos casos se había comenzado a extraer material por debajo de la línea del socavón. Muchas de las principales vetas dejaron ya de ser rentables y se abandonaron las obras. Pocos años más tarde, en 1687 o 1688, López de Quiroga decidió extender el socavón con una obra que finalizó hacia mediados de 1690, ya que pensaba que de ese modo accedería a mejores vetas. Hacia 1696 la plata registrada en la Caja de Potosí cayó abruptamente quizá como resultado del declive final de San Antonio. En este punto termina la información recabada por Bakewell, quien estuvo interesado en Antonio López de Quiroga, pero el asiento siguió funcionando intermitentemente (aunque nunca en los niveles que tuvo durante su apogeo) y fue abandonado recién en 1970. Todavía hoy se realizan algunos cateos y explotaciones marginales. Nuestro análisis se concentra en el periodo de apogeo que fue entre mediados de los años 1640 y fines de los años 1690 .

La tecnología utilizada en San Antonio para el beneficio de la plata fue la misma que estaba vigente en Potosí: la amalgama con mercurio. El mineral era extraído y llevado para su procesamiento a los ingenios, que eran complejos industriales donde se procesaba para separarlo de aquello que se consideraba sin valor. Primeramente se molía hasta convertirlo en polvo y posteriormente era mezclado en unos recipientes (cajones o buitrones), con agua, sal, otros minerales y mercurio. Esta mezcla se movía durante varios días y luego era lavada en enormes tinas donde se separaba la amalgama (la pella) del resto. Posteriormente se debía separar la plata del mercurio para lo cual se la lavaba, se exprimía en lienzos de Holanda o cañamazos, y se la destilaba. En San Antonio había otras formas de trabajar que implicaban menos inversión en infraestructura que los ingenios y que funcionaban en forma paralela aunque a pequeña escala: se podía moler en pequeños trapiches o utilizar la técnica de la fundición. 
$\mathrm{El}$ asiento estaba dividido en tres sectores residenciales que estaban íntimamente relacionados con la tecnología. ${ }^{19} \mathrm{El}$ principal -donde se encontraban las iglesias más importantes, la plaza y las viviendas de las autoridades- incluía algunos ingenios. En el Huaico Seco, en cambio (un anexo de San Antonio que se encontraba separado de este por una pequeña elevación donde se encontraban los principales accesos a las minas), solamente encontramos trapiches y algunos hornos de fundición. La quebrada de los ingenios, como su nombre lo indica, estaba conformada por la mayor parte de estos complejos alineados aguas abajo del socavón de López de Quiroga, en un pequeño río de aguas permanentes llamado Pucapirco. ${ }^{20}$ La población de los tres sectores era heterogénea en su composición étnica.

\section{El MUNDo DEL TRABajo En SAN ANTONio}

El asiento surgió en un territorio de población escasa, por lo que fue necesario llevar contingentes de trabajadores desde otros lugares desde un inicio. ¿Cuáles eran los mecanismos de atracción de trabajadores?, ¿existía coerción directa o esta funcionaba únicamente en forma indirecta a través de la tasación de los tributos en plata? En San Antonio hemos identificado diferentes modos de captación de mano de obra que son los que describiremos en este apartado con expresa distinción de los grados de coacción encontrados.

Son pocas las fuentes que nos permiten tener una idea general de cuáles fueron los mecanismos de reclutamiento de San Antonio, entre las que se destacan las dos visitas realizadas a fines del siglo XVII (la de 1683 ordenada por el virrey duque de La Palata, y la de 1689). En ellas se empadronaron únicamente a los tributarios y a sus familias, es decir, a una gran parte de los indígenas. ${ }^{21}$ La comparación entre estas visitas -que estaban separadas por unos pocos años- sugiere que muchos indígenas quedaron

${ }^{19}$ Hemos realizado dos campañas al sitio, una de ellas en el marco del proyecto de Cooperación Argentina-Francia, del Ministerio de Ciencia, Tecnología e Innovación Productiva y Ecos (Cooperación Bilateral de Investigación), código A08H05, "Gestión de recursos y producción de metal en el altiplano surandino entre los siglos X y XVIII: el ejemplo del Gran Lípez", director Axel Nielsen. La descripción del sitio se basa en dicha campaña y en las discusiones que tuvimos con los arqueólogos integrantes de la misma, en particular con Florian Tereygeol y Pablo Cruz. Además realizamos una segunda campaña con financiamiento de la Fundación John Simon Guggenheim y complementamos toda esta información con los informes de la Compañía Minera Lípez (de la década de 1880) que se encuentran en la Benson Latin American Collection, Rare Books, de la Universidad de Texas, Austin. 155.

${ }^{20}$ Así nombra el río el intendente Francisco de Paula Sanz, en Paula, "Descripción”, 1954, p.

${ }^{21}$ El primer padrón que incluye al conjunto de la población es de 1778, en plena decadencia del asiento, cuando la composición étnica del corregimiento había cambiado notoriamente. 
fuera de ellas ya sea porque residían en lugares a los que no llegaron las autoridades coloniales (y no fueron declarados por sus caciques), o porque la población se movilizaba mucho, lo que implicaba un recambio relativamente importante de trabajadores que no hemos podido captar en otras fuentes. Solamente $27 \%$ de los tributarios respondieron afirmativamente en 1689 a la pregunta de si habían sido empadronados por el corregidor durante la visita anterior. El porcentaje es muy bajo y si bien se pueden encontrar diversas explicaciones (incluyendo la posibilidad que no estuvieran respondiendo correctamente), hay que considerarlo si pensamos en la información cuantitativa que estamos obteniendo al procesarlas. Los aspectos cualitativos de las visitas, por su parte, son muy sugerentes para observar la organización de la mano de obra aunque no representan necesariamente a la mayoría de los casos.

Aunque las dos visitas realizadas a fines del siglo XVII tuvieron diferentes propósitos, coinciden en la identificación de tres categorías de tributarios que analizamos siguiendo la lógica de separar a quienes eran de Lípez y quienes no lo eran. En este corregimiento no se reportaron tributarios ausentes, y quienes pueden ser considerados migrantes a partir de su clasificación fiscal eran aproximadamente la mitad (véase cuadro 1).

A continuación comenzamos con la descripción de algunas características de los métodos de reclutamiento utilizados con los originarios y forasteros que se desprenden del análisis de las revisitas. Posteriormente incluimos otro conjunto de fuentes que sólo podemos evaluar de modo cualitativo y que no separa a los indígenas según su comunidad de pertenencia, sino más bien en grupos que responden a diferentes lógicas de la organización del trabajo.

\section{LOS ORIGINARIOS DE LÍPEZ}

Ambas visitas consideraron como originarios a los habitantes de los seis pueblos ubicados en torno al salar de Uyuni (en el repartimiento de San Cristóbal y en el de Llica y Tagua), esto es al norte del corregimiento, y a un pequeño grupo residente en el asiento. Dentro de este grupo de originarios es interesante separar el análisis en tres: los que vivían al sur del salar, los que estaban al norte del mismo y los del asiento.

Cuando se realizó el empadronamiento había muy pocos tributarios viviendo en los pueblos ubicados al sur del salar porque la mayoría (con sus familias) estaba viviendo en torno a las explotaciones mineras del sur, particularmente en las vecindades de San Antonio. Los tributarios declararon que no se les permitía volver a sus pueblos y que debían quedarse en el campo cerca del asiento cuidando los animales y trabajando en las minas 


\section{CUADRO 1. TRIBUTARIOS DE LÍPEZ EN 1683 Y 1689}

\begin{tabular}{lrr}
\hline Año visita & 1683 & \multicolumn{1}{c}{1689} \\
& & \\
Forasteros y yanaconas & $974(50 \%)$ & $1011(37 \%)$ \\
Originarios & $974(50 \%)$ & $1093(40 \%)$ \\
Sin especificar & - & $629(23 \%)$ \\
Total & 1948 & 2733 \\
\hline
\end{tabular}

Fuentes: Padrones de Lípez, en AGN, sala 13-18-6-5, año 1683, y sala 13-23-10-2, año 1689.

e ingenios, mientras que sus mujeres lo hacían en los trapiches. Como consecuencia de estas obligaciones en San Cristóbal se estaba perdiendo lo poco de la agricultura que aún quedaba porque no había ya quién se ocupara de ella.

A continuación transcribimos parte de las declaraciones que realizaron los originarios de Chuica, como ejemplo de lo que dijeron también los de los demás pueblos del sur del salar de Uyuni. Aunque es larga vale la pena transcribirla porque contiene elementos que sugieren la presencia de coacción.

[...] dijeron que casi todos los indios e indias muchachos y muchachas naturales de este pueblo de San Agustín de Chuica se hallan trabajando en el asiento de San Antonio de Lípez y demás partes de esta provincia en poder de diferentes personas así españoles como indios y aunque han hecho varias diligencias en orden de que vengan hallarse en tiempo de este padrón que está mandado hacer ni aun con el color de que vengan a sus fiestas que por este dicho mes se celebran en que siempre han recibido muchos agravios los curacas al querer sacarlos de dicho asiento [...] Y en cuanto a los ganados debajo del mismo juramento declaran tener hasta 600 cabezas de ganado de la tierra [...] [y que dicho ganado apacienta en diversos] parajes en que se hallan algunas ciénagas cortas y manantiales en que apenas se pueden sustentar, que dichos parajes son vecindades del asiento de San Antonio de Lípez donde los tienen para sus continuos trabajos así de bajas de metales, acarreos de leña, yareta y sal y otros materiales trabajando personalmente dejando las mujeres en los trapiches de dicho asiento hechas conires moliendo el metal a mano para poderse sustentar por cuya causa quedaba dicho pueblo despoblado y no asistía en él más que la gente de edad que van referida en dicho padrón [...].22

${ }^{22}$ Padrones de Potosí, desde 1611 hasta 1690, en AGN, sala 13-23-10-2. La ortografía de las citas textuales ha sido modernizada. 
El hecho de que estos pueblos hayan estado cerca del asiento puede haber sido la razón por la cual se ejerció más coacción sobre ellos que sobre otros indígenas. Estos lipeños, además, habían sido mineros desde tiempos prehispánicos, habían trabajado en minas coloniales regionales, y tenían animales de carga, todo lo cual los hacía una mano de obra deseable.

A diferencia de los originarios de estos pueblos del sur del salar, los de Llica y Tagua (ubicados al norte del mismo), en cambio, no parecen haber sufrido la misma presión, y su territorio fue en parte receptor de población. Los pueblos de Llica y Tagua habían sido afectados por lo menos desde la década de 1570 al trabajo en las minas cercanas llamadas Salinas de Garcimendoza, cuya producción era fluctuante. Hacia fines del siglo XVI parte de la población de los pueblos del sur del salar había sido llevada hacia el norte y se quedó viviendo allí. El visitador encontró en Llica y Tagua la producción más importante de quinua de la región. No se realizaron reclamos como los mencionados anteriormente (o no quedaron asentados en la visita), aunque sí había tributarios viviendo en San Antonio, sobre todo de Tagua.

El último grupo de originarios es el que dijo provenir del mismo San Antonio. Se trataba de un conjunto de indígenas que estaba sirviendo "a diferentes mineros y azogueros de este asiento por no saber su provincia ni reconocer curaca". ${ }^{23}$ En otras palabras, se trataba de tributarios de origen no reconocido, que al menos aparentemente habían roto sus lazos con sus comunidades, y que habían nacido en el asiento o que hacía mucho que estaban allí sirviendo a diferentes personas. El visitador los dejó a cargo de los mineros y azogueros hasta tanto se les designara autoridad.

Hay un cuarto grupo de indígenas que incluimos en este análisis de los originarios, que no fueron clasificados en la visita de 1689 y que no figuran en la de 1683. Nos interesa destacarlos porque conforman uno de los colectivos menos visibles en las fuentes coloniales del siglo XVII. Se trata de la población que en parte podría ser nativa de la región (del sureste de Lípez), y que no fue incluida en los padrones de originarios que como vimos corresponden a los pueblos del entorno del salar de Uyuni. Eran pastores especializados, quienes no debieron ofrecer muchas alternativas para la coacción porque podían desaparecer fácilmente en su inmenso territorio, tenían un gran poder de negociación y una organización social y política diferente a los de San Cristóbal. La posesión de llamas los convertía en una pieza clave de la economía minera en regiones altas y escasas de pasturas adecuadas para las mulas como Lípez. Es probable que ellos, así como también otros indígenas, aprovecharan las oportunidades que les brindaba la economía minera, insertándose en ella a conveniencia y trasladándose en función de

${ }^{23}$ Padrón de Lípez de 1602, en AgN, sala 13-18-6-5. 
las demandas. Hay algunos testimonios tempranos, sin embargo, que dan cuenta de la presión que estos mismos pastores sufrieron a partir de la saca de mujeres y jóvenes que hicieron los españoles para usarlas en el servicio doméstico, así como testimonios de una jurisdicción vecina (Chichas) donde retenían parte de la población de manera forzada en los ingenios donde se encontraban trabajando. ${ }^{24}$ Estos mecanismos muestran que además de existir la presión ejercida a través de las autoridades étnicas que ha sido objeto de numerosos análisis y que fue la manera más difundida de forzar a la gente a cumplir con sus obligaciones ${ }^{25}$ existían otras formas individuales o familiares de obligarlos al trabajo que han sido menos descritas en las fuentes. En particular la presión que se ejercía a través de las mujeres, que eran sacadas de sus hogares o retenidas por la fuerza como una manera de obligar a los hombres a trabajar.

\section{LOS FORASTEROS}

Uno de los primeros datos que surge del análisis de las visitas del siglo XVII a Lípez es que los forasteros, tributarios provenientes de otras comunidades o que habían nacido en dicho corregimiento como hijos de padres migrantes, habían llegado acompañados por sus familias y animales. Lamentablemente la información más rica de estas fuentes se recabó sólo para los hombres que pagaban tributo (o que debían hacerlo) que en su mayoría eran casados, pero se dice poco sobre sus mujeres e hijos. Entre otros datos conocemos el ayllu ${ }^{26}$ de origen y el lugar de nacimiento solamente de ellos, información que fue la base de los siguientes guarismos: $90 \%$ de los forasteros de la visita de 1689 dijo que provenía de provincias mitayas o de ciudades ubicadas en ellas, principalmente de Potosí, Oruro y Cuzco. Solamente 1\% sostuvo que había llegado desde provincias exentas y el resto declaró ser forastero nacido en Lípez. ${ }^{27}$

${ }^{24}$ Ibid., y "Visita que el licenciado don Martín de Arriola oidor de esta Audiencia tomó del ingenio nombrado Ntra. Sra. de Guadalupe provincia de los chichas propio del capitán Pedro de Espinoza y Ludueña para establecer las condiciones de trabajo, año de 1634", en Archivo y Biblioteca Nacionales de Bolivia (en adelante ABNB), Minas, 131, 1197.

${ }^{25}$ Saignes, "Caciques", 1985.

${ }^{26}$ El concepto de ayllu "remite a un principio de organización social propio de la tradición andina. En tanto principio de organización social, el ayllu está fundamentalmente relacionado con la dimensión parental de la vida social de los miembros que lo constituyen", en Sendon, "Ayllus”, 2009, p. 108. Si estos ayllus habían sido reducidos por Toledo o por alguna otra autoridad posterior, a sus tributarios se los reconocía como "originarios" de dicho pueblo de reducción.

${ }^{27}$ En el caso de la visita de La Palata los porcentajes son muy parecidos, pero no se consignaron los forasteros con lugar de nacimiento en Lípez. El 92\% de quienes tenían datos había nacido en alguna provincia mitaya, mientras que el restante $8 \%$ lo había hecho en una exenta. Gil Montero, "Pastores", 2011. 
A todos ellos se les preguntó por las causas de su migración y los testimonios fueron bastante homogéneos. La gran mayoría declaró haber llegado al asiento expulsado por las condiciones de esterilidad de sus provincias, y aprovechando las oportunidades que encontraban para poder ganarse la vida, pagar sus tributos o la exención de la mita. Por ejemplo, los originarios de Tarija declararon "que la mucha esterilidad de sus provincias los arrojaba a este asiento para buscar con su trabajo en minas, cargar sal, yareta y otros ejercicios para poder sustentarse". ${ }^{28}$ Según sus declaraciones, conocían a sus autoridades étnicas y cumplían con sus obligaciones coloniales. El único testimonio relativamente diferente fue el de los originarios de Arica, quienes llegaron con sus trajines de vino y se quedaron porque hallaron allí conveniencia y utilidades; si bien no se menciona la existencia de una coacción directa (no se los obligaba a ir específicamente a San Antonio), estos testimonios dan cuenta de la presión que ejercía el tributo en la población indígena, al obligarlos a salir a buscarse la vida para poder cumplir con sus obligaciones.

Las diferencias que encontramos entre el ayllu de origen y el lugar de nacimiento de los tributarios sugieren que estamos ante una población con una trayectoria migratoria larga y compleja, que a veces implicaba a más de una generación. Por ejemplo, de los 48 empadronados como originarios de la ciudad de Cuzco, solamente 14 habían nacido allí y el resto en lugares tan diversos como Potosí, Oruro, Carangas, Tolapampa o el mismo San Antonio. De los 97 originarios de la Villa de Oruro, solamente 34 habían nacido allí y el resto en la Villa de Oropesa (Cochabamba), La Paz, La Plata, Jesús Machaca, Potosí y otros pueblos pequeños. La identificación de su ayllu de origen y de la autoridad étnica sugiere que mantenían relación con sus comunidades y que era esta relación la que en parte garantizaba el cumplimiento de sus obligaciones fiscales. Lípez podría haber sido en su apogeo una alternativa, un lugar donde estos tributarios percibían mejores jornales cuando los centros tradicionales como Potosí u Oruro estaban produciendo menos y seguramente pagando menos. El cumplimiento generalizado del pago de los tributos y de las obligaciones de la mita que surge de las declaraciones sugiere, además, que si bien es probable que en la mayoría de los casos nadie los hubiera obligado a ir a San Antonio en particular, gran parte de los migrantes eligiera el asiento por las ventajas comparativas que ofrecía en relación con otros sitios que estaban en el momento en producción.

No todos reconocían a sus autoridades étnicas ni cumplían con las obligaciones. De la visita se desprende que efectivamente hubo algunos migrantes que declararon que no tributaban ni mitaban. En rigor eran

${ }^{28}$ Padrón de Lípez de 1602, en AGN, sala 13-18-6-5. 
pocos, y su porcentaje era mayor entre los que procedían de Cochabamba y entre los yanaconas, aunque la poca cantidad de casos puede influir en este resultado. ${ }^{29}$

Unos pocos años después de las visitas analizadas se realizó una encuesta en Potosí a los capitanes de la mayoría de las provincias mitayas. ${ }^{30}$ En este periodo, los capitanes de mita eran los responsables de "enterar los indios asignados", es decir, enviar a los azogueros la cantidad de trabajadores que les correspondía. En caso de no hacerlo, debían darle dinero para que pagase un reemplazo. En la encuesta se pueden observar aspectos de la cobranza de las obligaciones coloniales que no se perciben en la visita pero que ayudan a entender cómo pudieron ser posibles los altos porcentajes de cumplimiento de las obligaciones fiscales declarados, en el contexto de estas migraciones extendidas en el tiempo y en la geografía. Los capitanes sostenían que las autoridades étnicas sabían dónde estaban sus tributarios e iban a cobrarles los tributos o el reemplazo de la mita. Sin embargo, no siempre les enviaban el dinero a los capitanes para poder pagar efectivamente a los reemplazos y en muchos casos les hacían pagar más a los indios más ricos, por lo que solamente asistían a Potosí los pobres y desamparados. Los encuestados se quejaron por los abusos de los caciques y de los corregidores, quienes utilizaban en su beneficio a los tributarios perjudicando los enteros de la mita. Aunque estas declaraciones, como la mayoría de las que hemos trabajado, presentan algunos inconvenientes de interpretación por los intereses que estaban en juego y porque representan la voz de quienes las realizaron, la descripción de la participación de las autoridades y su conocimiento del paradero de muchos de sus tributarios coincide con otros testimonios.

Los capitanes denunciaron la existencia, además, de trabajo coactivo: Lípez y Oruro eran lugares a los que eran enviados los tributarios de Quillacas para trabajar "vendidos" por su gobernador, según indicaron en la cuarta pregunta: "[...] dijeron que los indios quillacas se han quejado de don Juan Francisco Choqueticlla, su gobernador, diciendo que los vende a los Lípez y a Oruro y otras partes y aunque tienen tierras bastante no vuelven por miedo del dicho gobernador [...]". ${ }^{31}$

Hemos encontrado en las visitas de fines del siglo XVII de Lípez a tributarios de dicho pueblo, pero sin ninguna indicación sobre este tema.

A partir de lo que dice esta encuesta, y lo expresado por los visitadores y los tributarios en tiempo de La Palata podemos decir, por un lado, que

\footnotetext{
${ }^{29}$ Los yanaconas que tributaban lo hacían a la corona y provenían de Oruro y de Potosí.

${ }^{30}$ Encuesta realizada en la Villa Imperial de Potosí el 11 de marzo de 1690, véase AGN, sala 13-23-10-2. Transcrita en Sánchez, Indio, 1973, pp. 65-149.

${ }^{31}$ Sánchez, Indio, 1973, p. 97.
} 
era relativamente común durante el siglo XVII que las autoridades étnicas recorrieran los diferentes lugares cobrando a "sus indios" lo que debían en concepto de exención de la mita y de tributos. Muchos de los tributarios que estaban trabajando en San Antonio o en los sitios relacionados pudieron haber ido en forma coordinada con sus autoridades, informándoles de sus destinos y facilitando el cobro de los tributos o la exención de la mita. Los abusos que supuestamente cometían las autoridades étnicas permiten proponer que pudo haber, también, tributarios que interrumpieron sus relaciones con la comunidad, sobre todo en los casos en los que la distancia al lugar de residencia era grande, que en nuestras fuentes podrían haber sido quienes declararon que no pagaban sus tributos ni reconocían cacique. En este caso las obligaciones coloniales no deberían haber presionado para migrar. Finalmente, la denuncia puntual de la encuesta sobre los quillacas que eran "vendidos" a Lípez da cuenta de casos en los que las mismas autoridades étnicas enviaron de modo forzado a los indígenas a trabajar a las minas.

\section{EL MUNDO DEL TRABAJO Y LAS FUENTES CUALITATIVAS}

La mayoría de los testimonios de las visitas realizadas durante fines del siglo XVII a San Antonio sugiere que había libertad de movimiento y de contratación, como si en algunos casos se hubiera tratado de un verdadero mercado de trabajo. Las voces que podemos identificar en estos documentos suelen ser pocas y sus testimonios muy parecidos. La ventaja que tienen estas fuentes es que nos muestran al conjunto de la población tributaria en un momento dado, lo que permite observar algunas situaciones que ocurrían en forma simultánea o realizar análisis cuantitativos. Otros documentos diversos que hemos consultado permiten escuchar voces mucho más variadas, que se contradicen entre sí o que muestran abundantes tonalidades de grises en las modalidades de reclutamiento de la mano de obra. En particular, uno de los aspectos más notables de estas fuentes es que la coacción aparece en ellas como una situación relativamente frecuente. Veamos algunos ejemplos.

A partir de la documentación del archivo sabemos que cuando se descubrió San Antonio se intentó llevar a trabajar al asiento a toda la gente que se pudo y que vivía en la cercanía, y además a los condenados a las panaderías, herrerías, obrajes y otros ejercicios que estaban en Potosí. ${ }^{32} \mathrm{El}$

\footnotetext{
${ }^{32}$ Expediente iniciado por los disturbios que promovió el nombramiento e ingreso del capitán Ignacio de Azurza al oficio de teniente de corregidor de Lípez, en ABNB, Minas, 131, 1200, año de 1649 .
} 
pedido de envío de condenados lo realizó el presidente de la Real Audiencia, quien sostenía que era importante ayudar a poblar el asiento "porque con los disturbios pasados se han huido muchos indios". ${ }^{33}$ Hay una breve referencia que sugiere, también, la presencia de otros métodos coactivos utilizados al menos con una parte de la población a través de la figura del "repartimiento de indios", que implicaba la adjudicación de tributarios a un español para que estuvieran a su servicio. Se trata de un pleito que realizaron los acreedores del capitán Ignacio de Azurza (que fue corregidor, dueño de ingenios y minas) después de su muerte, en el que la madre señala que gozaba del "repartimiento de cuatro indios". ${ }^{34}$

En San Antonio los azogueros sostenían que los problemas de escasez de mano de obra se agudizaban por su ubicación y condiciones ecológicas. Como este asiento estaba alejado de las provincias que podían proveer mano de obra y además tenía "algunas incomodidades de temperamento", hizo falta obligar a los indígenas a ir a trabajar a sus minas. Una de las formas de obligarlos fue la "cacería" de trabajadores, tal como se la definió en las fuentes. ${ }^{35} \mathrm{La}$ aplicación de este método para forzar a los tributarios a ir a San Antonio llevó a situaciones de abuso, textualmente "delitos graves pues saliendo los soldados sueltos en tropas y con prevención de armas en esta villa y por los caminos aprisionan a los indios que pueden sin atención al desamparo de sus mujeres e hijos y los llevan al dicho asiento donde como esclavos los venden a los mineros e ingenieros". Esta "cacería" no solamente escandalizó a quien redactó esta memoria, sino además afectaba a la mita potosina porque ni siquiera el corregidor tenía suficiente poder como para hacerlos volver a sus comunidades.

En numerosos juicios hemos visto que la población indígena tenía pocos márgenes de libertad en sus movimientos ya sea porque eran incluidos dentro de las propiedades cuando se vendían, porque eran retenidos en ellas por la fuerza o porque eran presionados para que se presentaran en determinados lugares de trabajo. El siguiente es un largo testimonio de una situación que hemos visto repetida en muchos casos y que ilustra algunos de los ejemplos mencionados en forma detallada:

Si saben que traía yo de labores en el cerro de Esmoruco cuando le vendí el dicho ingenio de 22 a 24 indios de labor, y en el ingenio del repaso otros tantos más o menos, y a las bajas de metales de diez a doce chacanires, y dos indios chacanires a la baja de la yareta y tres indios chacanires a la baja de la sal con ganado que

${ }^{33}$ Ibid. Véase ABNB, Minas, 131, 1200, año de 1649, f. 1.

${ }^{34}$ Autos correspondientes a los acreedores contra los bienes del capitán Ignacio de Azurza que murió en el asiento de los Lípez, año de 1667, en Archivo General de Indias (en adelante AGI), Escribanía, leg. 7, Pleitos de la Plata, núm. 12.

${ }^{35}$ Don Francisco de Sarmiento al virrey, Potosí, 31 de julio de 1654, en AGI, Charcas, 58. 
yo les había dado para que me lo pagasen en las dichas bajas, y el dicho ganado pasan además de 1200 carneros. Asimismo si saben que le di diez indios atacamas con más de 200 mulas para el avío del ingenio y beneficio de metales. Asimismo si saben que además de los indios arriba dichos tenía yo en mi ingenio indios para morteros y para los hornos de las lamas indios que las molían para quemarlas e indios que cortaban yareta e indios para guardar el ganado y que toda esta gente arriba que pasaban de 65 personas de trabajo y sus mujeres e hijos me los sacó así de las labores de Esmoruco como del dicho ingenio llevándolos por fuerza unos a su estancia que tiene en jurisdicción de los chichas y otros al ingenio de Jaquegua, y dando muchachos e indias a quien le ha parecido como probaré cuando importe con otras cosas por cuya causa se han huido y muerto muchos por haberlos sacado de a donde muchos de ellos eran naturales y otros estaban ya naturalizados con grande daño mío y de los acreedores y de los reales quintos de su majestad. ${ }^{36}$

En esta declaración se puede observar no solamente que en la venta del ingenio se incluyó algo que se podría clasificar como un "derecho al uso de la mano de obra", sino además que los indígenas estaban muy fuertemente sujetos a los movimientos y necesidades de los mineros.

Hay un expediente que describe diferentes formas de reclutar mano de obra y de retenerla en las labores, que es el juicio que le hizo Antonio López de Quiroga a Álvaro Espinoza de Patiño por dinero que le debía de la construcción del socavón. ${ }^{37}$ Si bien este caso es especial, ya que se trataba de la "compañía de los socavoneros" destinada a construir la obra específica para desaguar las minas, puede ser considerado un interesante muestrario: la mayoría de ellos fue conchabada en Potosí y llevada a la obra, gracias a las ofertas de mejores jornales y a los adelantos de pago que se les hacía. Para López de Quiroga este método era indispensable porque Lípez era "paraje aborrecido de los indios y de donde huían antes con extremo". ${ }^{38}$ Debido a la mala fama que tenía el asiento, el azoguero había conchabado a "silleros, zapateros, arpistas y ladrones" a quienes era muy difícil (léase costoso) retener en la obra. Para buscar trabajadores se equipaba a personas con mulas y carpas para el viaje, cebada para los animales y adelanto de avío para los futuros conchabados. Las pérdidas declaradas por la compañía de socavoneros se refieren a los avíos entre-

${ }^{36}$ Juan Gutiérrez de Bohorques provincia de los Lípez sobre las minas y el ingenio que vendió a Antonio Farfán de los Godos en el asiento de San Antonio de Padua provincia de los Lípez y este debe devolverle por no haber cumplido con las condiciones fijadas de la venta, años de 1652-1654, en ABNB, Minas, 57, 394, fs. 67v y 68.

${ }^{37}$ El maestro de campo Antonio López de Quiroga contra don Álvaro Espinoza de Patiño sobre la parte que a este le toca en los gastos del socavón que ambos daban en el asiento de San Antonio del Nuevo Mundo, años de 1679-1681, en ABNB, Minas, 58, 405.

${ }^{38}$ Ibid., f. 71. 
gados y perdidos por los indígenas huidos y muertos, y a los gastos que ocasionaba montar las operaciones de búsqueda de los que se escapaban. Sostener a los indígenas en el lugar, declaraba el azoguero, implicaba una serie de gastos avalados por la costumbre, como por ejemplo la plata que se les daba por sus fiestas, casamientos y entierros; "las máscaras morrones y lo demás que se hizo para divertimiento de los indios y fiestas que le celebran con estos trajes a su usanza y costumbre"; las velas que se daban para entierros y misas de devociones; la yerba y azúcar que se les daba cuando estaban "enfermos de comer". En ocasiones se contrataba mano de obra para trabajar en las minas, pero luego se los utilizaba en el socavón.

La minería no era la única alternativa que tenía un tributario para juntar el dinero necesario y de hecho muchos de ellos lo ganaban comerciando en las ciudades o trabajando en los trajines. Pero la minería era una de las principales formas de ganar buenos jornales en plata (sobre todo en algunos oficios especializados) y así poder cumplir con las obligaciones, por ello estos asientos pudieron ser lugares donde llegaban tributarios no solamente obligados sino en forma voluntaria. El abasto, el acarreo dentro de los asientos y el de algunos insumos que se conseguían en lugares cercanos eran otra forma de ganar dinero o de complementar los ingresos. Gran parte del abastecimiento de larga distancia de alimentos (harina, vino, frutas, maíz) y de insumos para la minería (mercurio, herramientas de hierro, maderas para la construcción, etc.) se realizaba con llamas, así como el acarreo de minerales de la boca mina para ser procesados en los ingenios y molinos, o el abasto local de sal y combustible. La articulación de pastoreo y minería, que existía ya desde tiempos prehispánicos, debió favorecer la presencia de algunos grupos que llegaban con experiencia en el trabajo minero y de beneficio de los minerales, y también con sus animales. Los asientos mineros ofrecían también otras alternativas mencionadas en los documentos: la de explotar vetas, robar, vender o beneficiar minerales en forma clandestina y conseguir así también plata.

\section{DISCUSIÓN}

El contexto demográfico en el que San Antonio se descubrió tuvo su apogeo y comenzó su decadencia, fue el de las migraciones masivas de tributarios que acompañaron al declive de la población originado en la conquista. Esta situación era conocida por las autoridades, en particular por Melchor de Navarra y Rocaful, duque de La Palata, quien fue designado por el rey Carlos II en 1680 como virrey de Perú con la misión de realizar una visita general y un nuevo repartimiento de mita. Se consideraba que estas acciones eran la condición indispensable para revitalizar la minería 
potosina que se encontraba en declive ${ }^{39}$ En sus memorias el virrey hizo referencia con preocupación al despoblamiento de los Andes que se había tornado evidente y tomó partido en la discusión acerca de sus causas; reconocía que las provincias más perjudicadas habían sido aquellas afectadas por la mita, pero distinguía el "desamparo de los pueblos" del hecho de haberse acabado los indios. Para él lo que estaba ocurriendo era que huían con facilidad a "tierras de infieles" o a las provincias exentas donde podían evitar cumplir con su obligación. ${ }^{40}$

El procesamiento de los datos de la visita de La Palata que realizaron diferentes historiadores reforzó la visión del virrey, las provincias que más se habían despoblado en el largo siglo que había transcurrido entre Toledo y La Palata habían sido efectivamente las mitayas; una parte de la población indígena había muerto y otra parte se había redistribuido alterando no solamente los antiguos patrones de distribución, sino también las clasificaciones tributarias. ${ }^{41}$ En el caso de San Antonio hemos visto lo mismo, la mita potosina fue indudablemente el factor que más influyó en las migraciones del siglo XVII, afectando a las provincias mitayas y orientando el flujo de migrantes hacia Lípez, que estaba exenta. Lo que nuestro caso de estudio discute -por lo menos en parte- es la serie de motivos que impulsó a esta población a moverse. Parte de estos motivos conforman la respuesta a nuestra pregunta inicial, es decir, la descripción de los mecanismos que promovieron la llegada de trabajadores indígenas a este asiento, que estaba tan alejado de las regiones centrales y cuyas condiciones de vida eran tan inclementes.

Las obligaciones fiscales fueron una de las principales causas de la migración indígena, aunque no lo fueron en el sentido que indicó el virrey duque de La Palata. Hay por lo menos tres tipos de evidencia en San Antonio que sugieren que los tributarios buscaban diferentes modos de cumplir con ellas y no de evitarlas. La primera es su propia declaración que indica que $90 \%$ estaba cumpliendo con sus obligaciones tributarias y con el pago del reemplazo de la mita. Con todo derecho se podría discutir la veracidad de esta declaración, ya que podría convenir a los tributarios declarar el pago de obligaciones para no sufrir represalias. Las respuestas negativas, sin embargo, y su distribución en el conjunto de los empadronados sugieren que esta expresión no fue absolutamente falsa. Pero además tenemos otra parte de su testimonio que apunta en el mismo sentido, que es el de las razones por las cuales habían llegado a San Antonio. Allí se podían encontrar recursos para alimentarse -declararon los indígenas- vestirse, "pasar

\footnotetext{
${ }^{39}$ Cole, "Viceregal", 1984.

${ }^{40}$ Navarra y Rocaful, Memoria, 1859.

${ }^{41}$ Sánchez, Indios, 1978, y Evans, "Migration”, 1990.
} 
la vida" y pagar lo adeudado. La tercera evidencia proviene de otra fuente, la encuesta de 1690, que describe los mecanismos a través de los cuales las autoridades étnicas buscaban completar los pagos recorriendo la región y cobrándoles a sus tributarios lo que debían. El conjunto de estas evidencias avala la hipótesis que afirma que fue la necesidad de pagar el tributo y la exención de la mita lo que impulsaba a que al menos una parte de los indígenas vendiera su fuerza de trabajo o su producción y funcionaba por ello como un mecanismo indirecto de forzarlos a trabajar.

Hay otro testimonio muy interesante por el tipo de fuente, una visita a ingenios y minas, que también avala esta hipótesis. Aunque no se realizó en San Antonio sino en el vecino corregimiento de Chichas unos pocos años antes del descubrimiento de nuestro asiento, la riqueza de esta documentación, la cercanía de estos ingenios y el hecho que los inversores y los azogueros hubieran trabajado también en Lípez nos permite presentarla como una evidencia factible y muy interesante por lo poco frecuente. Esta visita fue realizada en 1634 por don Martín de Arriola a dos ingenios donde estaban trabajando indígenas provenientes de los más variados rincones del virreinato de Perú, con una clara mayoría de las provincias vecinas de Lípez y Atacama y un poco menos de Porco y del Tucumán. ${ }^{42}$ Habían llegado para trabajar "voluntariamente para tener con qué pagar sus tasas" y aprovechaban también los jornales para "comprar lana para sus mujeres". Los tributos eran cobrados por las autoridades étnicas esporádicamente (sólo se menciona la presencia de los kurakas de Lípez y de Atacama) y pagados por el dueño del ingenio, en el caso de esta visita, el capitán Pedro de Espinosa y Ludueña. Este último aspecto es el que resulta más interesante, porque en cierto modo explica por qué las migraciones eran convenientes para casi todos: el azoguero contaba con la mano de obra que necesitaba pagando los tributos de sus trabajadores (que no eran muy elevados) y podía retenerlos por la deuda que contraían con él a partir de este pago; las autoridades étnicas cobraban las obligaciones y podían responder ante los oficiales reales; finalmente, los azogueros potosinos recibían la plata de los reemplazos de aquellos mitayos que estaban trabajando en otros sitios.

La organización de la mita tuvo otra influencia importante en los desplazamientos de población ya que funcionaba como el inicio de un circuito migratorio que muchas veces se extendía por generaciones. Si bien la mayoría de los mitayos que acudía a Potosí desempeñaba tareas que re-

\footnotetext{
${ }^{42}$ Visita que el licenciado don Martín de Arriola oidor de esta Audiencia tomó del ingenio nombrado Nuestra Señora de Guadalupe provincia de los Chichas propio del capitán Pedro de Espinoza y Ludueña para establecer las condiciones de trabajo, véase ABNB, Minas, 131, 1197, y también Minas, 131, 1198.
} 
querían poco conocimiento, muchos de ellos aprendían allí algunas especialidades o algunas nuevas técnicas que les permitían trabajar como mingas cuando no estaban afectados a la mita. Allí podían enterarse, además, si se descubría un nuevo mineral que requiriese de los conocimientos que habían adquirido, para ir a conchabarse y mejorar sus ingresos. Muchos mineros y azogueros iban a Potosí a abastecerse y a buscar mano de obra, especialmente en los casos que necesitaban trabajadores especializados en la tecnología de la amalgama, la construcción de socavones de desagüe o el manejo de la pólvora. Potosí funcionó como una escuela empírica para quienes iban a trabajar allí y los conocimientos que los indígenas adquirían les servían para conseguir ventajas relativas en los minerales que estaban en apogeo, como era el caso de San Antonio.

El virrey duque de La Palata hizo hincapié en la libertad que supuestamente tenían los indígenas que les permitía moverse de modo tal de evitar cumplir con sus obligaciones. Los testimonios que vimos sobre San Antonio, en cambio, muestran que una parte importante (pero difícil de cuantificar) de los tributarios era llevada a través de diferentes mecanismos para trabajar donde hacía falta. Uno de los mecanismos era lisa y llanamente la saca de indios que vivían más o menos cerca de las minas, como fue el caso de los originarios del sur del salar de Uyuni. A ellos no se les permitía volver a sus pueblos y debían quedarse a trabajar obligados por diferentes mecanismos, entre los que se mencionó la retención de familiares. Las "cacerías de indios" y el envío de condenados también entran en esta clasificación de migración forzada para trabajar en San Antonio.

También hay casos en nuestros testimonios que dan cuenta de aspectos atractivos de San Antonio que favorecían la migración, entre ellos la buena paga, la existencia de mercado para la venta de alimentos, la oportunidad de trabajo. La libertad de algunos consistía en elegir en dónde trabajar (en una determinada mina, en una hacienda, en un ingenio), y no tanto elegir entre trabajar para los españoles o quedarse en sus pueblos dedicados al trabajo agrario.

Estos mecanismos descritos en el trabajo son válidos para la coyuntura específica que estamos analizando, esto es, para el siglo XVII que tenía una serie de características que cambiaron mucho en el siglo posterior. Una de ellas era que los ingresos fiscales generados por la producción minera eran los más significativos de las Cajas Reales de Charcas, superando los dos tercios en muchos años, mientras que los tributos, en cambio, no llegaban a 5\%. ${ }^{43}$ La preocupación mayor de los funcionarios reales, que se convirtió por momentos en obsesión, era mantener y aumentar los quintos reales, que era el principal impuesto aplicado a la producción de plata. Lo

${ }^{43}$ Klein, Finanzas, 1994. 
prioritario era, por ello, facilitar el acceso a la mano de obra a los mineros y azogueros, aun cuando no se cumplieran las ordenanzas más básicas relativas al trabajo indígena en las minas, que sostenían que debía ser libre.

\section{CONCLUSIONES}

A lo largo del trabajo hemos identificado diferentes formas de reclutamiento de la mano de obra para el asiento minero de San Antonio. Según las normas, este asiento debería haber contado únicamente con mano de obra voluntaria ya que no había un sistema particular de trabajo forzado como la mita potosina. La práctica, sin embargo, nos mostró que el reclutamiento tuvo diferentes formas y una variedad de opciones entre las coactivas y las voluntarias.

Dentro del conjunto de los originarios de Lípez propusimos que los más afectados habían sido los que vivían al sur del salar de Uyuni, porque fueron forzados a migrar y a quedarse en la cercanía del asiento perdiendo, así, una parte importante de su producción agrícola. Los del norte del salar, por su parte, habían estado afectados a las minas de Salinas de Garcimendoza en forma intermitente desde la década de 1570 y también tuvieron que ir a San Antonio, aunque no presentaron reclamos ni su economía parece haberse perjudicado en el mismo grado que la de los del sur del salar. Finalmente, el conjunto de los nacidos en la región minera de San Antonio, que no siempre fue clasificado como originario, tampoco presentó reclamos probablemente porque no fueron alejados de sus lugares de residencia habitual.

Los migrantes, por su parte, mostraron también un conjunto heterogéneo de razones por las cuales habían llegado al asiento a trabajar. Considerando la totalidad de los testimonios vimos casos de migración forzada (los quillacas, los que fueron víctima de las "cacerías" de trabajadores, los condenados), de atracción a partir de una mejor oferta de jornales y de algunos otros beneficios, o porque allí se podían encontrar modos de ganarse la vida (parte de los trabajadores de la compañía de socavoneros, la mayoría de los forasteros de las visitas y los yanaconas), y de retención forzada (a través de las deudas por el pago del tributo por parte de los españoles, los huidos que fueron buscados y llevados al asiento, o quienes fueron obligados a partir de la presión ejercida sobre sus familiares).

La condición de tributario fue la que justificó casi todas estas formas de reclutamiento y la que relativiza la calidad de libre de cualquier forma de trabajo indígena. En ocasiones esta condición se relacionaba en forma directa con los sistemas forzados de trabajo (en los repartimientos de indios o en las "cacerías" descritas) y a veces en forma indirecta a 
partir de la necesidad de venta de mano de obra para poder cumplir con su pago o con el reemplazo de la mita. Esta institución, finalmente, fue de enorme influencia en las migraciones ya que casi la totalidad de los forasteros provenía de las provincias afectadas.

\section{FUENTES CONSULTADAS}

\section{Archivos}

ABNB Archivo y Biblioteca Nacionales de Bolivia, Sucre, Bolivia.

AGI Archivo General de Indias, Sevilla, España.

AGN Archivo General de la Nación, Buenos Aires, Argentina.

\section{Bibliografía}

Assadourian, Carlos Sempat, "La organización económica espacial del sistema colonial” en Carlos Sempat Assadourian, El sistema de la economía colonial. El mercado interior, regiones y espacio económico, México, Nueva Imagen, 1983, pp. 255-306. "La despoblación indígena en Perú y Nueva España durante el siglo XVI y la formación de la economía colonial”, Historia Mexicana, El Colegio de México, vol. 38, núm. 3, 1989, pp. 419-453.

Bakewell, Peter, Minería y sociedad en el México colonial. Zacatecas (1546-1700), México, Fondo de Cultura Económica, 1976. , "Mining in Colonial Spanish America" en L. Bethell (ed.), The Cambridge History of Latin America, vol. 2, Colonial Latin America, Cambridge, Cambridge University Press, 1984, pp. 105-151. , Miners of the Red Mountain. Indian Labour in Potosi, 1545-1650, Albuquerque, University of New Mexico Press, 1984.

Plata y empresa en el Potosí del siglo XVII. La vida y época de Antonio López de Quiroga, Pontevedra, Exma. Diputación de la Provincia de Pontevedra, 1988.

Barnadas, Josep M., Charcas, orígenes históricos de una sociedad colonial, La Paz, Centro de Investigación y Promoción del Campesinado, 1973.

Bonilla, Heraclio, Los Andes en la encrucijada. Indios, comunidades y Estado en el siglo XIX, Ecuador, Libri Mundi/Facultad Latinoamericana de Ciencias Sociales, 1991.

Brown, Kendall, A History of Mining in Latin America. From the Colonial Era to the Present, Albuquerque, University of New Mexico Press, 2012.

Buren, Mary VAn, "Rethinking the Vertical Archipelago. Ethnicity, Exchange and History in the South Central Andes", American Antropologist, vol. 98, núm. 2, 1996, pp. 338-351. 
Cole Jefrerey A., "Viceregal Persistence versus Indian Mobility: The Impact of the Duque de la Palata's Reform Program on Alto Peru, 1681-1692", Latin American Research Review, vol. 19, núm. 1, 1984, pp. 37-56.

The Potosi Mita, 1573-1700: Compulsory Indian Labor in the Andes, Stanford, CA, 1985.

Escobari de Querejazu, Laura, "Los extravagantes. Mano de obra en las minas de Oruro, 1606-1650", Tiempos de América, núm. 1, pp. 1997, 11-23.

Evans, Brian, "Migration Process in Upper Peru in the Seventeenth Century" en DAVID Robinson (ed.), Migration in Colonial Spanish America, Cambridge, Cambridge University Press, 1990, pp. 62-85.

Garner, Richard L., "Long-term Silver Mining Trends in Spanish America: A Comparative Analysis of Peru and Mexico", American Historical Review, vol. 93, núm. 4, 1988, pp. 898-935.

Gavira MárQuez, María Concepción, "Reclutamiento y remuneración de la mano de obra minera en Oruro, 1750-1810" en Anuario de Estudios Americanos, vol. 57, núm. 1, 2000, pp. 223-250.

"Potosí y Oruro a principios del siglo XVII", Tiempos de América, vol. 14, 2007, pp. 3-20.

,"La población del corregimiento de Carangas (virreinato del Río de la Plata) a fines del siglo XVIII", América Latina en la Historia Económica, vol. 17, núm. 1, enero-junio de 2010, pp. 67-89.

Gil Montero, Raquel, "Los pastores frente a la minería colonial temprana: Lípez en el siglo XVII" en LaUtaro Nuñez y Axel Nielsen, En ruta. Arqueología, historia y etnografía del tráfico surandino, Córdoba, Encuentro Grupo Editor, 2011, pp. 285-312.

Klein, Herbert, Las finanzas americanas del imperio español, 1680-1809, México, Instituto de Investigaciones Dr. José María Luis Mora/Universidad Autónoma Metropolitana, 1994.

Medinacelli, Ximena, Sariri. Los llameros y la construcción de la sociedad colonial, Lima, Agencia Sueca para el Desarrollo Internacional/Instituto Francés de Estudios Andinos, Plural Editores/Instituto de Estudios Bolivianos, 2010.

Mumford, Jeremy Ravi, Vertical Empire. The General Resetlement of Indians in the Colonial Andes, Durham y London, Duke University Press, 2012.

Murra, John, Formaciones económicas y políticas del mundo andino, Lima, Instituto de Estudios Peruanos, 1975.

Navarra y Rocaful, Melchor, Memoria de los virreyes que han gobernado el Perú durante el tiempo del coloniaje español, t. II, Don Melchor de Navarra y Rocaful, duque de La Palata, Lima, Librería Central de Felipe Bailly, 1859.

Paula Sanz, Francisco De, "Descripción de las provincias de la Audiencia de Charcas, 1780-1781", con nota de Gunnar Mendoza, Boletín de la Sociedad Geográfica Sucre, t. XLV, núm. 441, enero-marzo de 1954, Bolivia, pp. 122-166. 
Rowe, John Howland, "The Incas under Spanish Colonial Institutions", Hispanic American Historical Review, Duke University, vol. 37, núm. 2, 1957, pp. 155-199.

SÁnchez Albornoz, Nicolás, El indio en el Alto Perú a fines del siglo XVII, Lima, Seminario de Historia Rural Andina, 1973.

Indios y tributos en el Alto Perú, Lima, Instituto de Estudios Peruanos, 1978.

Saignes, Thierry, "Caciques, tribute and Migration in the Southern Andes. Indian Society and the $17^{\text {th }}$ Century Colonial Order (Audiencia de Charcas)", Ocassional Papers, University of London, núm. 15, 1985.

"Review: The Miners in Colonial Potosî", Bulletin of Latin American Research, vol. 6, núm. 1, 1987, pp. 89-92.

"Ayllus, mercado y coacción colonial: el reto de las migraciones internas en Charcas (siglo XVII)" en Olivia Harris, Brooke Larson y EnriQue TANDETER (eds.), La participación indígena en los mercados surandinos: estrategias y reproducción social, siglos XVI a XX, La Paz, Centro de Estudios de la Realidad Económica y Social, 1987, pp. 111-158.

Sendon, Pablo, "Los ayllus de la porción oriental del departamento del Cusco. Aproximación comparativa desde el Collasuyu", Bulletin de l'Institut Français d'Études Andines, vol. 38, núm. 1, 2009, pp. 107-130.

TANDeter, EnRIQUe, Coacción y mercado. La minería de la plata en el Potosí colonial, 16921826, Buenos Aires, Sudamericana, 1992.

"Los ciclos de la minería de metales preciosos: Hispanoamérica" en ENRiQue Tandeter y Jorge Hidalgo Lehuedé (dir.), Historia general de América Latina, España, Organización de las Naciones Unidas para la Educación, la Ciencia y la Cultura, 2000, vol. IV, pp. 127-148.

Zagalsky, PAula C., "Mita potosina y tributo indígena: dos imposiciones coloniales con trayectorias divergentes (Charcas, siglos XVI-XVII)", ponencia presentada en XXIII Jornadas de Historia Económica y III Congreso Latinoamericano de Historia Económica, Bariloche, 23 al 26 de octubre de 2012.

ZulAWSKY, ANN, "Forasteros y yanaconas: la mano de obra de un centro minero en el siglo XViı" en Olivia Harris, Brooke Larson y EnriQue Tandeter (eds.), La participación indígena en los mercados surandinos: estrategias y reproducción social, siglos XVI a XX, La Paz, Centro de Estudios de la Realidad Económica y Social, 1987, pp. 159-191.

"Wages, Ore Sharing, and Peasant Agriculture: Labor in Oruro's Silver Mines, 1607-1720", Hispanic American Historical Review, vol. 67, núm. 3, agosto de 1987, pp. 405-430.

, They Eat from their Labor. Work and Social Change in Colonial Bolivia, Pittsburgh, University of Pittsburgh Press, 1995. 